\title{
LEARNING BY WALKING - POKÉMON GO AND MOBILE TECHNOLOGY IN FORMAL EDUCATION
}

\author{
Peter Mozelius, Sofia Bergström-Eriksson, Jimmy Jaldemark \\ Mid Sweden University (SWEDEN)
}

\begin{abstract}
Peripatetic group learning has a long history that dates back to the walking sessions that Plato and Aristotle led in the Lyceum of Athens. Other teachers in ancient Greece also frequently used play and physical training didactically. Pokémon Go has a relatively short history (starting in the summer of 2016), but this location-based game had a faster global spread than anyone could have imagined. In the first week after its release, the game became the most downloaded app in history. In Pokémon Go, the players use real-world maps on which buildings, roads and water are correctly indicated. The game is played on mobile devices; the Pokémon figures pop up on maps and can be captured with virtual balls. To catch the Pokémon figures, players must physically move to the place where the figure is located; thus, unlike most other digital games, Pokémon Go involves outdoor activities such as long walks.

With its high degree of physical activity, Pokémon Go has attracted researchers' attention for use as an exergame. Several researchers are also looking at Pokémon Go's use as an augmented-reality game. In this study, the focus is on Pokémon Go's use as a mobile-learning game and on the potential for outdoor activities in formal education. In this study, two primary school classes used the game for learning sessions in mathematics and social science. The aim of this study is to discuss students' expressions regarding how a location-based game such as Pokémon Go could be used as a tool for outdoor activities in formal education.

Each primary school class was divided into groups of three to four students each for planned lessons that included walks. Each group had one or two smartphones to stimulate collaboration between students. The walks included PokéStops where teachers conducted planned sessions; later, the teachers followed up on the outdoor lessons within a traditional classroom setting. Data were gathered from group interviews with the students who participated in the outdoor sessions involving Pokémon Go. The collected data were then analysed and categorised via a thematic analysis.

The findings show that Pokémon Go can be seen as a learning-stimulating game that could augment traditional teaching sessions in formal education. Students reported that they enjoyed catching the Pokémon figures the most, but some students also mentioned that they appreciated the math assignments and liked learning about the statues that they passed during the walkings. The most positive findings were that there were concrete learning outcomes and that this mobile, game-based educational setting seemed to encourage students to engage in collaborative learning. However, Pokémon Go is not an all-encompassing solution for the ongoing digitalisation of primary school. The conclusion is rather that location-based games have the potential to vitalise formal education, provided that they are carefully integrated into the curriculum.
\end{abstract}

Keywords: Game-based learning, location-based games, mobile learning, outdoor learning, peripatetic group learning, Pokémon Go.

\section{INTRODUCTION}

Play-based learning and physical training were frequently used didactic ideas way back in ancient Greece. The best-known are the peripatetic sessions that Plato and Aristotle led in the Lyceum of Athens. The term 'peripatetic' means "walking about place to place, traveling on foot" [1]; the concept of peripatetic education also has been brought up in the $21^{\text {st }}$ century, with the motivation that walking can stimulate discussion and collaboration [2].

In earlier research, the use of digital games has often been associated with a sedentary lifestyle and a risk of obesity $[3,4]$. On the other hand, several studies during the last decade have explored digital games that are designed to encourage physical activities, also called 'exergames' [5-7]. One game that has been studied in this context is Pokémon Go $[8,9]$. 
Researchers have looked at Pokémon Go as both an augmented-reality game [10,11] and a locationbased game [12]. Several location-based games have been developed in the last decade, but Pokémon Go was the first blockbuster success in the field [12]. Pokémon Go was released in June 2016, and its rapid global spread caused lively discussions in various media. Within its first week of release, Pokémon Go became the most downloaded mobile app in history.

The game uses real-world maps on which roads, buildings and lakes are correctly depicted. These maps are combined with gameplay in the fantasy world from which the Pokémon figures originate (based on a Japanese collectible card game) [13]. In Pokémon Go, the monster figures that pop up on the screen can be captured with the use of virtual balls. To catch the figures, players must physically move to the real-world location where the figures are marked on the map.

\subsection{Aim}

The aim of this study is to discuss students' expressions regarding how a location-based game such as Pokémon Go could be used as a tool for outdoor activities in formal education.

\section{EXTENDED BACKGROUND}

Game-based learning (GBL) and mobile learning (ML) are both much-hyped research fields in, and they are often discussed separately. In this study, the concepts of GBL and ML have been combined to investigate the inclusion of social perspectives of learning and peripatetic group learning in the orchestration of didactic designs in educational settings.

\subsection{Game-based learning}

Applications of GBL have been evaluated, with promising results, in a broad range of educational contexts [14, 15]. GBL should preferably be seen, not as a standalone concept but as a promising idea that should be combined with other learning methodologies (Sierra et al., 2016). An interesting extension of GBL is to involve social perspectives so as to emphasise learning as a social practice based on dialogue [16].

A straightforward and frequently used idea for GBL is to purchase and use so called commercial offthe-shelf (COTS) games [17]. For history and language learning, general topics can be learnt by just playing games, but for many subjects, COTS games need to be combined with tailor-made assignments. For this study, teachers designed suitable teaching sessions and assignments for mathematics and social science subjects (such as civics, local history and religion) based on the use of the standard Pokémon Go game.

\subsection{Mobile learning}

The relationship between mobility and learning has been studied under various names aside from ML, including 'augmented learning', 'seamless learning' and 'ubiquitous learning'. In this paper, however, $\mathrm{ML}$ is used. Whatever term is used to discuss this field, it has evolved since the early trials in the mid1970s [18]. ML comprises the application of various mobile technologies. Nevertheless, this emphasis on it acting as a technology-dependent view of learning is misleading. ML is characterised by an emphasis on learning as a collaborative and dialogical phenomenon. This phenomenon links learning to five contextual aspects as they are dispersed over time: conceptual space, physical space, social space, technology and learning $[19,20]$. These five aspects of context support an understanding of $\mathrm{ML}$ as a flexible, dynamic and emerging phenomenon that encourages humans to perform dialogues about various issues and concepts in various social groups, with the help of various technologies, across time and in various locations.

Since the start of the current millennium, the ML field has gone through rapid development, including studies that have linked mobile applications and devices to learning in formal, informal and non-formal educational settings. Therefore, it can be argued that $\mathrm{ML}$ is a phenomenon that blurs the boundaries of learning to include formal educational, working and leisure settings [21]. Researchers in the field have primarily focused on handheld devices such as smartphones and tablets but have paid less attention to various wearable technologies such as smart glasses and smartwatches. Wearables are "technologies as embodied companions that become extensions of the self" [22]. The emergence of wearables within ML has been influenced by developments related to the Internet of Things. 
In the current study, ML is applied in two ways. First, the study includes the use of smartphones, with the students and teachers using their own equipment (in a so-called bring-your-own-device approach). This also means that the study includes various smartphone platforms. Second, the students' and teachers' actions during the study were captured using wearable technology. So-called spy glasses were used to record audio and video, as well as to capture the participants' movements and dialogues.

\subsection{Location-based games and Pokémon Go}

The rapidly expanding fields of GBL and ML have many branches, one of which involves teaching through location-based games (LBGs). Mobile LBGs are often built around the idea of mapping realworld actions onto a parallel, virtual game world where players are entertained; interactions mainly occur at special points of interest (POIs). Navigation between POls often involves the use of physical or digital maps [23]. The LBG category includes exergames, augmented-reality games such as Zombie Run [24], and dedicated educational games such as Frequency 1550 [25].

The most well-known LBG is Pokémon Go, which has been classified as an exergame [8, 9] and as an augmented-reality game [10]. A few LBGs existed before Pokémon Go, but it was the first global blockbuster in the genre [12], as it acquired 100 million users within a few weeks after its release in June 2016 [11]. The game is built around a combination of realistic real-world maps and a fantasy world that includes the Pokémon monsters from the Japanese collectible card game of the same name. In Pokémon Go, a collection of virtual monsters pops up on the user's mobile screen. The user captures these virtual Pokémon figures using virtual balls. To reach higher levels, the players need to visit real-world POls to capture virtual monsters and earn game points.

\section{METHOD}

The overall research strategy was a case-study approach, with two outdoor learning and teaching sessions as case units. Participants in the learning activities were students and teachers from one fifth-grade and one sixth-grade class (aged 11 and 12 years), as well as researchers from Mid Sweden University. A case study is an exploration of a real-world phenomenon [26] (an activity or a process) that is analysed in depth using a combination of data-gathering methods [27].

\subsection{Data collection}

To support the results discussed in this paper, data were collected using semi-structured interviews. This method embraces the idea that interviews are interactive communication sessions in which researchers lead the communication by asking questions [28]. This interview method allows for a broad data set to be collected from a relatively small number of informants. Therefore, this study was based on six group interviews with a total of eighteen primary school students. These interviews were conducted immediately following each outdoor session. Their purpose was to capture the students' experiences and perceptions regarding the sessions. The interviews focused on issues such as what the students thought about the outdoor session, what they learned, and whether they liked wearing the spy glasses.

This research project also included video recordings of the outdoor sessions. During these sessions, students and teachers wore spy glasses to capture data such as the communications between students or the documents and applications that they worked with, all from the wearers' perspectives. A researcher also participated in each outdoor session, recording the group's actions as a whole with a handheld video camera to get a complete picture of the various perspectives collected from the spy glasses' video. The video material from the observations, when combined with the lesson plans that the teachers created, enables a description of what the students and teachers actually did when they played Pokémon Go in the outdoor-based lesson. Nevertheless, in the current paper, only the interviews were analysed and discussed. However, the data from the video recordings and the lesson plans were used to create the Orchestration of the Walking Sessions section of this paper.

\subsection{Data analysis}

The patterns and themes were identified and categorised through an inductive thematic analysis. Unlike deductive thematic analysis, which is based on theory and research, inductive analysis is data driven [29]. Compared to content analysis, thematic analysis has a stronger focus on identifying the patterns and categories that have the most direct associations with the research aim. In this study, the 
themes were categorised according to how they related to the discussion regarding students' statements about how a LGB such as Pokémon Go could be used as a tool for outdoor sessions in formal education.

Thematic analysis is one of the most frequently used methods in qualitative research; the basic idea is to identify patterns and themes that can be useful to achieve the research aim. This study's thematic analysis was carried out using the six phases that Braun and Clarke [29] described: 1) become familiar with your data, 2) generate preliminary codes, 3) identify patterns and themes, 4) review those themes, 5) define and name the categories, and 6) present the analysis.

\section{ORCHESTRATION OF THE WALKING SESSIONS}

In accordance with the changing conditions of childhood, the teaching profession is under pressure to change. In addition to implementing planned teaching activities and communicating knowledge, today's teachers are increasingly asked to design learning opportunities. This type of design is discussed here in terms of the orchestration of learning, a process of coordinating resources with the intention to support learning [e.g., 30, 31]. Subsequently, each teacher in this study was instructed to design a lesson in either social science or mathematics. The teachers were asked to consider a learning plan in which the students would be expected to be outdoors, use smartphones and Pokémon Go LBG, and work in small groups of three to four students. Furthermore, each student group would have one to two smartphones to hand in. The purpose of having only one or two devices per group was to stimulate collaboration among students.

The lessons were planned as walks that would build on the PokéStops in the vicinity. When a student group passed each planned stop, its teacher tried to attract the students' attention to it. Before the walk, the students were instructed to prepare for various tasks related in either social science or mathematics. For example, they were asked to make certain calculations related to both Pokémon Go and the vicinity. One group counted the number of cars during the walk. In addition to the planned assignments, the walking sessions also included discussions of issues that the students brought up spontaneously. The teachers utilised these moments to capture ideas that spontaneously came to their minds during the walks. After all the groups had completed the orchestrated route, the students and teachers met in their classrooms for follow-up lessons. This happened within a few days of the initial walk. During the follow-up lessons, the teachers brought up the issues that arose during the walks and discussed the events of the outdoor session with the students.

\section{RESULTS}

The thematic analysis revealed patterns, which were grouped into the five categories that are depicted in Figure 1 below. The categories are presented and discussed in order of relevance; learning outcomes, Pokémon Go and orchestration are the most important categories. Technology-enhanced learning and mobile games and gender are less grounded in the analysed data, but both are part of the resulting analysis.

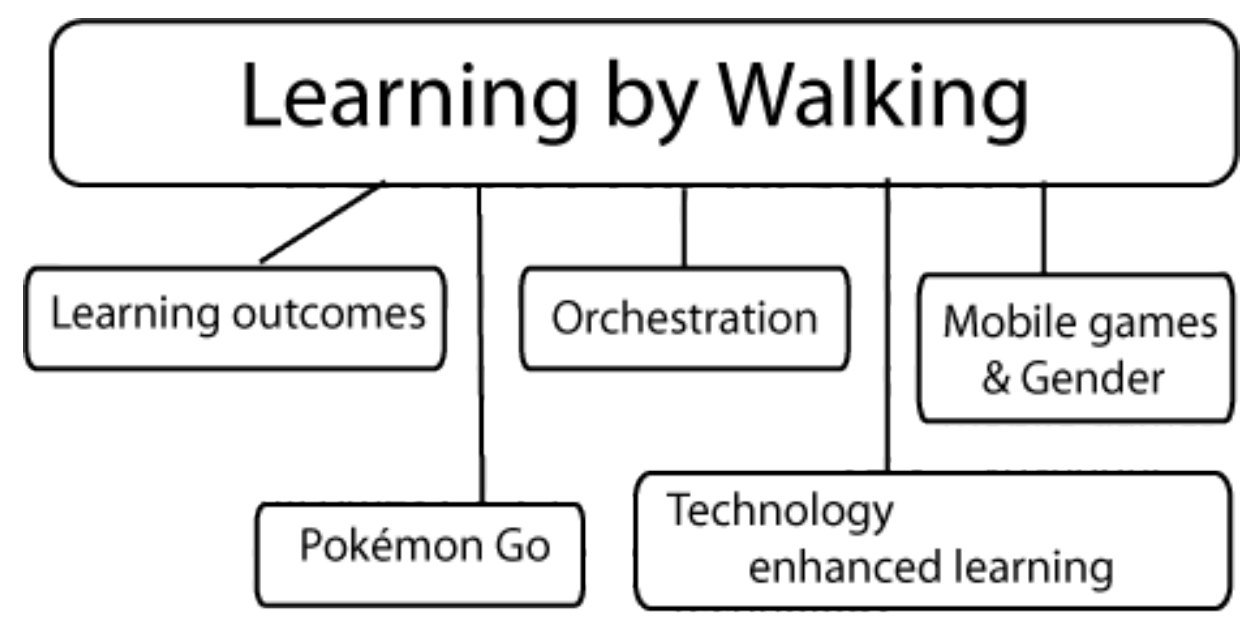

Figure 1. Categories of the thematic analysis 


\subsection{Learning outcomes}

The most positive finding was the presence of clear learning outcomes in both mathematics and social science. One of the boys answered the question about what he had learnt by saying, "Well history, we learnt about history and also a bit of geography." Another boy remembered, "I found a 'Dragon' by the Franzén statue ... I caught it with five balls". A girl summarised the learning outcomes as follows: "We learnt more about the statues, earlier we only knew that there was a statue at these locations".

The learning outcomes from the math sessions were more concrete and more directly aligned to the gameplay. The assignments in these sessions were based on how much of their Pokémon Go resources the students had spent to catch the monsters or hatch the eggs in the game. These math assignments often involved calculating percentages or transforming fractions into percentages. Here is an example of a question used in a math session: "If you have completed $40 \%$ of the distance for a 5$\mathrm{km}$ egg, how far have you walked, and how many kilometers do you still need to walk?"

Students also counted cars; one student claimed, "I don't find the PG game to be the most interesting, but rather the counting of the cars". The car-counting also led to interesting further discussions about topics such as the impact that cars have on the environment.

\subsection{Pokémon Go}

The students' fascination with the game was obvious in their interview answers, and several students made claims such as these: "I know the game pretty well" or "I started playing shortly after the release in the summer of 2016". On the other hand, some gave answers such as, "I played mostly during the summer, now, I've stopped and it's deleted from my mobile" or "I used to play a lot, but after a while I got fed up, and the game took a lot of space on my mobile". These answers harmonise with the Pokémon Go hype curve [32] shown in Figure 2.

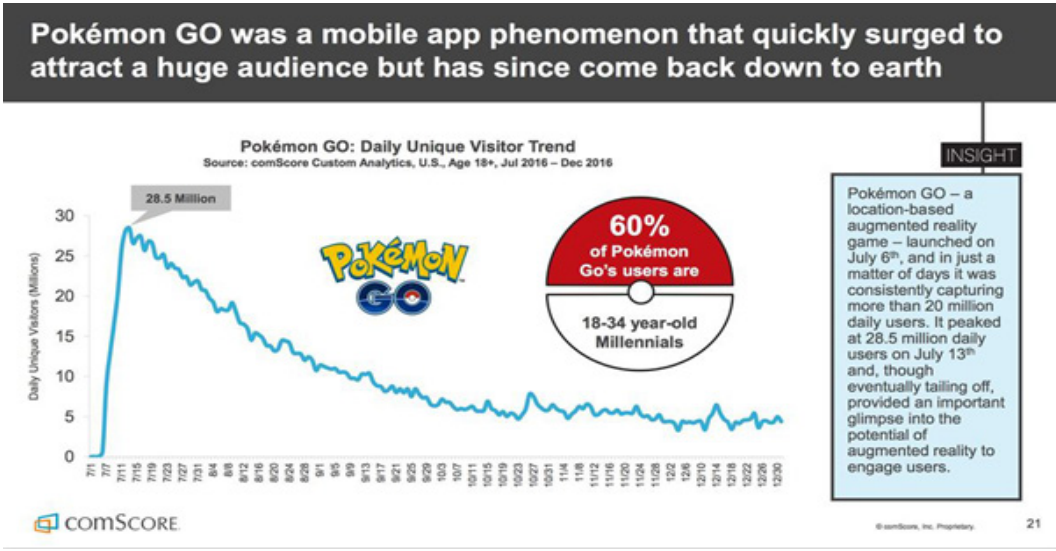

Figure 2. The Pokémon Go hype curve

Some answers were related to the Swedish climate: "I played for quite a while but stopped when it got colder" and "When it came and got trendy, it was summer and warm, and you were out walking with friends, yes, that was more fun than what it is now".

\subsection{Orchestration}

The students, in addition to showing positive attitudes towards the Pokémon Go game, also gave positive feedback on the outdoor activity's design: "Felt good to be outdoors and to get some fresh air" and "Could be good to get some physical exercise". The common denominator seems to be an appreciation for variety, as there were also comments such as these: "The ordinary Social Science lessons are really boring" and "We are more tired after an ordinary lesson, now we are still alert".

Students also appreciated the collaborative setup of the outdoor activities and liked the idea of outdoor group learning. A didactic mantra in the Swedish school tradition is "Repetitio est mater studiorum" ("Repetition is the mother of study"). This study's findings indicate that it is worth considering whether repetition should be replaced with variation, though not all learning activities should be game-based outdoor activities. The Latin motto for the young, mobile generation could be "Bis repetita non placent" ("Repetitions are not appreciated"; Horatius Quintus Flaccus, Ars Poetica). 


\subsection{Technology-enhanced learning}

Students' discussions regarding how to use technology in school and which technologies should be used were surprisingly mature. Their ideas were sometimes a bit futuristic ("Teachers will be robots"), but others included realistic reasoning ("There will be more electronics, and our teachers have to learn how to use it'). In the ongoing digitalisation of Swedish primary schools, the teachers' professional development is an issue, as many teachers find it stressful to keep up to date. Three of the boys had an illustrating discussion:

Boy 1 and Boy 2: "Yes, we have smart boards."

Boy 1: "But they are not smart."

Boy 3: "Can't you use them?"

Boy 2: "Not that good."

Boy 1: "No."

Boy 2: "Teachers have not actually learnt much, or what the problems are so sometimes they don't know what HDMI is, then I have to click on something before it works. They can stand there for something like 5 minutes trying to figure out what's wrong".

The students' discussions about which hardware devices to use resembled the teachers' discussions on the same topic. For activities such as the ones used in this study, mobile phones were preferred, even if Pokémon Go could run on a tablet. In several other contexts (including as a gaming platform), however, the students seemed to have a preference for tablets. Finally, as one boy pointed out, in some situations, laptops definitely are better than either phones or tablets. This also illustrates the current hardware dilemma in which computational thinking should be introduced as a mandatory subject in primary school via computer programming. Smartphones and tablets are great for LBGs but not optimal for programming exercises. Few schools have the resources for 1-to-1 computing, and most schools have a mix of various hardware devices.

\subsection{Mobile games and gender}

As mentioned earlier, there were gender differences in the students' attitudes. The boys often mentioned game features: "We spent a lot of 'Stardust' to beat our competitors" and "You can get more eggs, and the master plan is about completing the Pokédex". However, the girls rarely mentioned any details of the gameplay, and their comments were more along these lines: "I've never played myself, but joined others when playing Pokémon Go"; another girl answered a question about whether she could play by herself with a hesitating "Maybe".

This difference should be further investigated via video analysis, but it is notable that a gender difference can also be found in the Pokémon Go Statistics Report [33] shown in Figure 3 below.

\section{Pokémon GO players by gender}

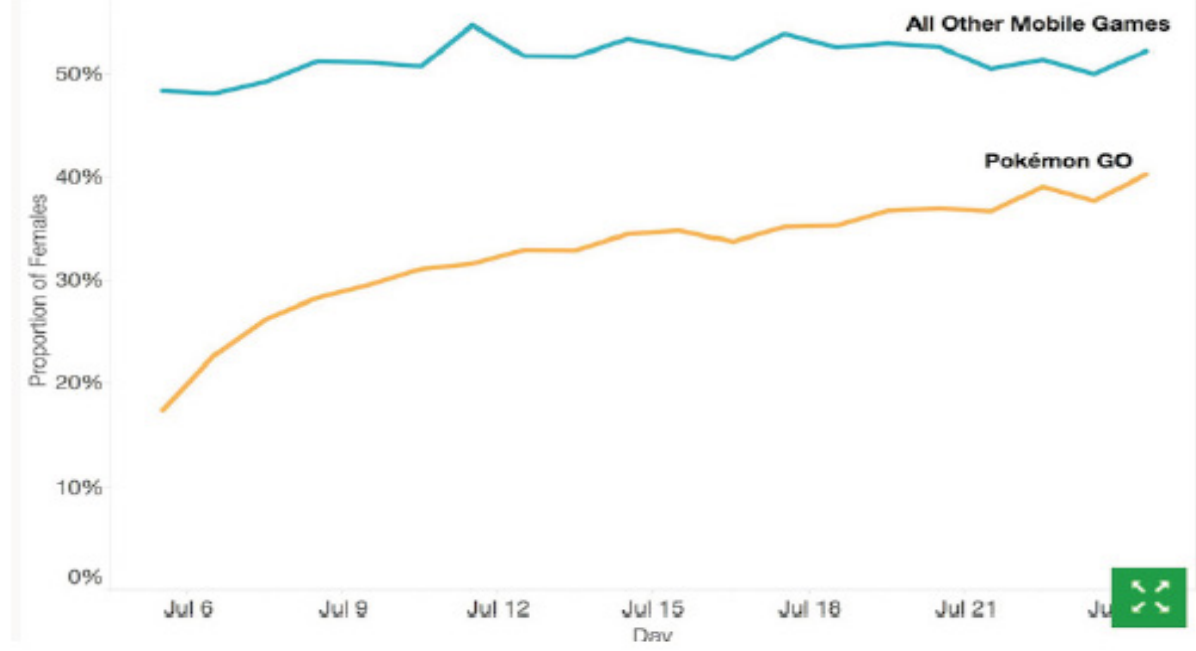

Source: TechCrunch

Figure 3. Players by gender in Pokémon Go and in other mobile games 


\section{CONCLUSIONS AND FUTURE WORK}

Mobile game-based learning seem to have the potential to enhance formal education for $5^{\text {th }}$ and $6^{\text {th }}$ graders, which agrees with what Meluso et al. [34] found in another study. The most positive findings relate to the learning outcomes, as almost all the interviewees expressed that they learned from the outdoor sessions. Pokémon Go is the most popular LBG, but it is far from the only one that can be used for outdoor orchestrations of learning. This study's main finding is thus that the described orchestration could support formal learning sessions in core primary school subjects.

\subsection{Future work}

In addition to the interviews that comprise the data analysed in this paper, this study produced an extensive amount of video recordings, which consist of videos recorded using spy glasses and handheld devices. This video material will expand the understanding gained from analysis of the interview data. In future video analyses, various aspects of the students' actions will be made clear, including how the students interacted with each other, how they used the mobile technologies, how they interacted with the game, and how and what they perceived in the physical environment during the walking sessions. The upcoming analyses will address other perspectives, including gender, with the aim of understanding variations in how boys and girls understand and use mobile technologies within the learning processes in formal education.

\section{REFERENCES}

[1] Pocock, R. W, (2002). Education system and method for home schoolers and the like. U.S. Patent No. 6,464,505. Washington, DC: U.S. Patent and Trademark Office.

[2] Carreiro, K. Learning more walking between classes Journal of Philosophy and History of Education, 55 (2005), 31-48.

[3] Telama, R., Nupponen, H. and Piéron, M. Physical activity among young people in the context of lifestyle. European Physical Education Review, 11, 2 (2005), 115-137.

[4] Tremblay, M. S. and Willms, J. D. Is the Canadian childhood obesity epidemic related to physical inactivity? International Journal of Obesity, 27, 9 (2003), 1100-1105.

[5] Chao, Y.-Y., Scherer, Y. K. and Montgomery, C. A. Effects of using Nintendo Wii ${ }^{\mathrm{TM}}$ exergames in older adults: A review of the literature. Journal of Aging and Health, 27, 3 (2015), 379-402.

[6] Staiano, A. E. and Calvert, S. L. Exergames for physical education courses: Physical, social, and cognitive benefits. Child Development Perspectives, 5, 2 (2011), 93-98.

[7] Vernadakis, N., Papastergiou, M., Zetou, E. and Antoniou, P. The impact of an exergame-based intervention on children's fundamental motor skills. Computers \& Education, 83 (2015), 90-102.

[8] Althoff, T., White, R. W. and Horvitz, E. Influence of Pokémon Go on physical activity: Study and implications. Journal of Medical Internet Research, 18, 12 (2016).

[9] Wong, F. Y. Influence of Pokémon Go on physical activity levels of university players: A crosssectional study. International Journal of Health Geographics, 16, 8 (2017), 1-12.

[10] Serino, M., Cordrey, K., McLaughlin, L. and Milanaik, R. L. Pokémon Go and augmented virtual reality games: A cautionary commentary for parents and pediatricians. Current Opinion in Pediatrics, 28, 5 (2016), 673-677.

[11] Zsila, Á., Orosz, G., Bőthe, B., Tóth-Király, I., Király, O., Griffiths, M. and Demetrovics, Z. An empirical study on the motivations underlying augmented reality games: The case of Pokémon Go during and after Pokémon fever. Personality and Individual Differences (In press), 1-11.

[12] Colley, A., Thebault-Spieker, J., Lin, A. Y., Degraen, D., Fischman, B., Häkkilä, J., Kuehl, K., Nisi, V., Nunes, N. J. and Wenig, N. The geography of Pokémon GO: Beneficial and problematic effects on places and movement. ACM, Denver, CO, 2017.

[13] Kent, S. L. The ultimate history of video games: From Pong to Pokémon and beyond... the story behind the craze that touched our lives and changed the world. Three Rivers, New York, 2010.

[14] Tobias, S., Fletcher, J. D. and Wind, A. P. Game-based learning. Springer, New York, 2014. 
[15] Vogel, J. J., Vogel, D. S., Cannon-Bowers, J., Bowers, C. A., Muse, K. and Wright, M. Computer gaming and interactive simulations for learning: A meta-analysis. Journal of Educational Computing Research, 34, 3 (2006), 229-243.

[16] Amory, A. Game object model version II: A theoretical framework for educational game development. Educational Technology Research and Development, 55, 1 (2007), 51-77.

[17] Van Eck, R. Digital game-based learning: It's not just the digital natives who are restless. EDUCAUSE Review, 41, 2 (2006), 1-16.

[18] Chiang, F. K., Zhu, G., Wang, Q., Cui, Z., Cai, S. and Yu, S. Research and trends in mobile learning from 1976 to 2013: A content analysis of patents in selected databases. British Journal of Educational Technology, 47, 6 (2016), 1006-1019.

[19] Kakihara, M. and Sorensen, C. Mobility: An extended perspective. IEEE, Big Island, Hawaii, 2002.

[20] Kukulska-Hulme, A., Sharples, M., Milrad, M., Arnedillo-Sánchez, I. and Vavoula, G. The genesis and development of mobile learning in Europe. Information Science Reference, Hershey, PA, 2011.

[21] Jaldemark, J. Contexts of learning and challenges of mobility: Designing for a blur between formal and informal learning. Springer, New York, 2018.

[22] Bower, M. and Sturman, D. What are the educational affordances of wearable technologies? Computers \& Education, 88 (2015), 343-353.

[23] Nadarajah, S. G., Overgaard, B. N., Pedersen, P. W., Hansen Schnatterbeck, C. G. and Rehm, M. Enriching location-based games with navigational game activities. Springer, Cham, 2017.

[24] Laine, T. H. and Sedano, C. I. Distributed pervasive worlds: The case of exergames. Journal of Educational Technology \& Society, 18, 1 (2015), 50-66.

[25] Huizenga, J., Admiraal, W., Akkerman, S. and Dam, G. Mobile game based learning in secondary education: Engagement, motivation and learning in a mobile city game. Journal of Computer Assisted Learning, 25, 4 (2009), 332-344.

[26] Yin, R. K. Case study research: Design and methods. Sage, London, 2009.

[27] Creswell, J. W. Research design: Qualitative, quantitative, and mixed methods approaches. SAGE, London, 2014.

[28] Johannesson, P. and Perjons, E. A design science primer. CreateSpace, Stockholm, 2012.

[29] Braun, V. and Clarke, V. Using thematic analysis in psychology. Qualitative Research in Psychology, 3, 2 (2006), 77-101.

[30] Bezemer, J. and Kress, G. Multimodality, learning and communication: A social semiotic frame. Routledge, London, 2015.

[31] Littleton, K., Scanlon, E. and Sharples, M. Orchestrating inquiry learning. Routledge, London, 2012.

[32] Nintendo life (2017). Fresh data shows that four out of five Pokémon GO players have given up hunting (Retrieved 20/09/2017)

http://www.nintendolife.com/news/2017/04/fresh_data_shows_that_four_out_of_five_pokemon_ go_players_have_given_up_hunting

[33] Business of Apps (2016). Pokémon Go Statistics Report City, (Retrieved 21/09/2017) http://www.businessofapps.com/pokemon-go-usage-revenue-statistics/

[34] Meluso, A., Zheng, M., Spires, H. A. and Lester, J. Enhancing 5th graders' science content knowledge and self-efficacy through game-based learning. Computers \& Education, 59, 2 (2012), 497-504. 